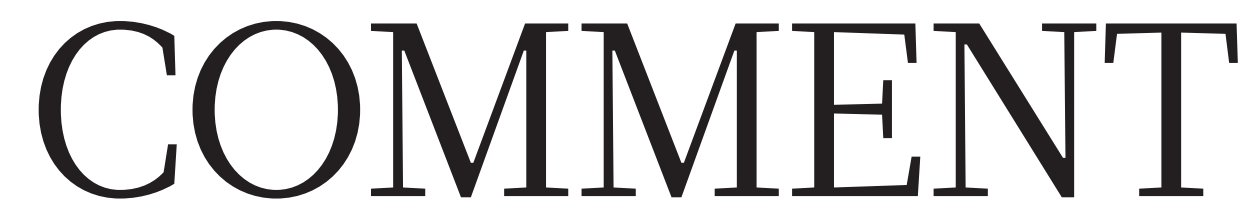

PoLICY Twenty tips to help non-scientists to assess evidence $\mathbf{p . 3 3 5}$
FICTION Brave New World

reappraised 50 years after

Aldous Huxley's death p.338
HISTORY How science and technology have changed surfing $\mathbf{p . 3 4 1}$
EDUCATION Data show massive open online courses mainly reach educated males $\mathbf{p . 3 4 2}$
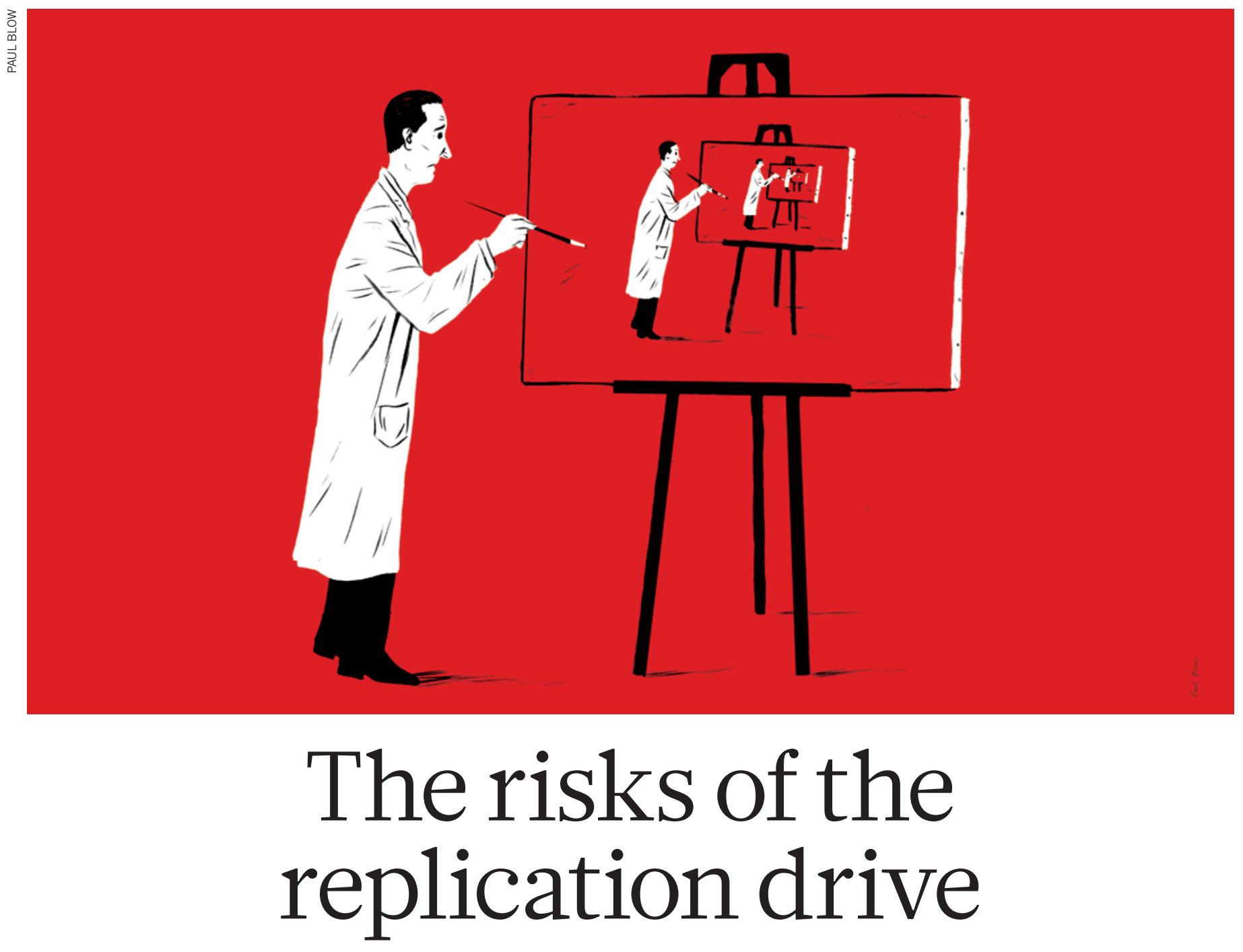

The push to replicate findings could shelve promising research and unfairly damage the reputations of careful, meticulous scientists, says Mina Bissell.

$\mathrm{E}$ very once in a while, one of my postdocs or students asks, in a grave voice, to speak to me privately. With terror in their eyes, they tell me that they have been unable to replicate one of my laboratory's previous experiments, no matter how hard they try. Replication is always a concern when dealing with systems as complex as the three-dimensional cell cultures routinely used in my lab. But with time and careful consideration of experimental conditions, they, and others, have always managed to replicate our previous data.

Articles in both the scientific and popular press $^{1-3}$ have addressed how frequently biologists are unable to repeat each other's experiments, even when using the same materials and methods. But I am concerned about the latest drive by some in biology to have results replicated by an independent, self-appointed entity that will charge for the service. The US National Institutes of Health is considering making validation routine for certain types of experiments, including the basic science that leads to clinical trials ${ }^{4}$. But who will evaluate the evaluators? The Reproducibility Initiative, for example, launched by the journal PLoS ONE with three other companies, asks scientists to submit their papers for replication by third parties, for a fee, with the results appearing in PLoS ONE. Nature has targeted ${ }^{5}$ reproducibility by giving more space to methods sections and encouraging more transparency from authors, and has composed a checklist of necessary technical and statistical information. This should be applauded. 
So why am I concerned? Isn't reproducibility the bedrock of the scientific process? Yes, up to a point. But it is sometimes much easier not to replicate than to replicate studies, because the techniques and reagents are sophisticated, time-consuming and difficult to master. In the past ten years, every paper published on which I have been senior author has taken between four and six years to complete, and at times much longer. People in my lab often need months - if not a year - to replicate some of the experiments we have done on the roles of the microenvironment and extracellular matrix in cancer, and that includes consulting with other lab members, as well as the original authors.

People trying to repeat others' research often do not have the time, funding or resources to gain the same expertise with the experimental protocol as the original authors, who were perhaps operating under a multi-year federal grant and aiming for a high-profile publication. If a researcher spends six months, say, trying to replicate such work and reports that it is irreproducible, that can deter other scientists from pursuing a promising line of research, jeopardize the original scientists' chances of obtaining funding to continue it themselves, and potentially damage their reputations.

\section{FAIR WIND}

Twenty years ago, a reproducibility movement would have been of less concern. Biologists were using relatively simple tools and materials, such as pre-made media and embryonic fibroblasts from chickens and mice. The techniques available were inexpensive and easy to learn, thus most experiments would have been fairly easy to double-check. But today, biologists use large data sets, engineered animals and complex culture models, especially for human cells, for which engineering new species is not an option.

Many scientists use epithelial cell lines that are exquisitely sensitive. The slightest shift in their microenvironment can alter the results - something a newcomer might not spot. It is common for even a seasoned scientist to struggle with cell lines and culture
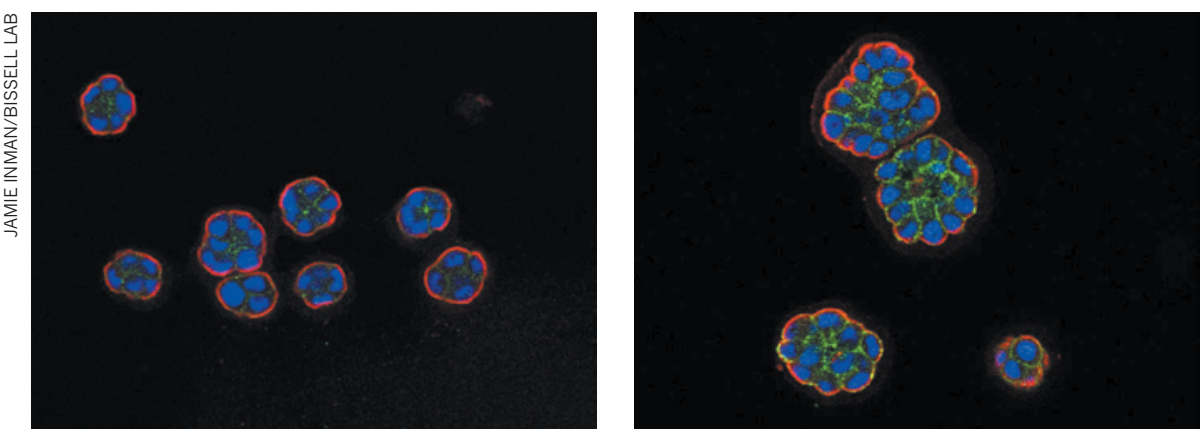

Cells from the same human breast cell line from different sources respond differently to the same assay.

conditions, and unknowingly introduce changes that will make it seem that a study cannot be reproduced. Cells in culture are often immortal because they rapidly acquire epigenetic and genetic changes. As such cells divide, any alteration in the media or microenvironment - even if minuscule - can trigger further changes that skew results. Here are three examples from my own experience.

My collaborator, Ole Petersen, a breastcancer researcher at the University of Copenhagen, and I have spent much of our scientific careers learning how to maintain the functional differentiation of human and mouse mammary epithelial cells in culture. We have succeeded in cultivating human breast cell lines for more than 20 years, and when we use them in the three-dimensional assays that we developed ${ }^{6,7}$, we do not observe functional drift. But our colleagues at biotech company Genentech in South San Francisco, California, brought to our attention that they could not reproduce the architecture of our cell colonies, and the same cells seemed to have drifted functionally. The collaborators had worked with us in my lab and knew the assays intimately. When we exchanged cells and gels, we saw that the problem was in the cells, procured from an external cell bank, and not the assays.

Another example arose when we submitted what we believe to be an exciting paper for publication on the role of glucose uptake in cancer progression. The reviewers objected to many of our conclusions and results because the published literature strongly predicted the prominence of other molecules and pathways in metabolic signalling. We then had to do many extra experiments to convince them that changes in media glucose levels, or whether the cells were in different contexts (shapes) when media were kept constant, drastically changed the nature of the metabolites produced and the pathways used ${ }^{8}$.

A third example comes from a non-malignant human breast cell line that is now used by many for three-dimensional experiments. A collaborator noticed that her group could not reproduce its own data convincingly when using cells from a cell bank. She had obtained the original cells from another investigator. And they had been cultured under conditions in which they had drifted. Rather than despairing, the group analysed the reasons behind the differences and identified crucial changes in cell-cycle regulation in the drifted cells. This finding led to an exciting, new interpretation of the data that were subsequently published ${ }^{9}$.

\section{REPEAT AFTER ME}

The right thing to do as a replicator of someone else's findings is to consult the original authors thoughtfully. If e-mails and phone calls don't solve the problems in replication, ask either to go to the original lab to reproduce the data together, or invite someone from their lab to come to yours. Of course replicators must pay for all this, but it is a small price in relation to the time one will save, or the suffering one might otherwise cause by declaring a finding irreproducible.

When researchers at Amgen, a pharmaceutical company in Thousand Oaks, California, failed to replicate many important studies in preclinical cancer research, they tried to contact the authors and exchange materials. They could confirm only $11 \%$ of the papers ${ }^{3}$. I think that if more biotech companies had the patience to send someone to the original labs, perhaps the percentage of reproducibility would be much higher.

It is true that, in some cases, no matter how meticulous one is, some papers do not hold up. But if the steps above are taken and the research still cannot be reproduced, then these non-valid findings will eventually be weeded out naturally when other careful scientists repeatedly fail to reproduce them. But sooner or later, the paper should be withdrawn from the literature by its authors.

One last point: all journals should set aside a small space to publish short, peer-reviewed reports from groups that get together to collaboratively solve reproducibility problems, describing their trials and tribulations in detail. I suggest that we call this ISPA: the Initiative to Solve Problems Amicably.

Mina Bissell is Distinguished Scientist in the Life Sciences Division, Lawrence Berkeley National Laboratory, Berkeley, California 94720, USA. e-mail:mjbissell@lbl.gov

1. Naik, G. 'Scientists' Elusive Goal: Reproducing Study Results' The Wall Street Journal (2 December 2011); available at http:// go.nature.com/aqopc3

2. Nature Med. 18, 1443 (2012).

3. Begley, C. G. \& Ellis, L. M. Nature 483, 531-533 (2012).

4. Wadman, M. Nature 500, 14-16 (2013)

5. Nature 496, 398 (2013)

6. Barcellos-Hoff, M. H., Aggeler, J., Ram, T. G. \& Bissell, M. J. Development 105, 223-235 (1989).

7. Petersen, O. W., Rønnov-Jessen, L., Howlett, A. R. \& Bissell, M. J. Proc. Natl Acad. Sci. USA 89, 9064-9068 (1992)

8. Onodera, Y., Nam, J.-M. \& Bissell, M. J. J. Clin. Invest. (in the press)

9. Ordinario, E. et al. PLoS ONE 7, e51786 (2012). 